\title{
Administration of protein hydrolysates from Palmaria palmata reduced food intake, improved glycaemic parameters and lipid profile in streptozotocin diabetes induced mice
}

Dietary proteins play vital roles in metabolism, energy efficiency and body composition. Increased protein intake has resulted in greater weight loss versus lower protein intakes, including calorie-restrictive diets, resulting in increased fat-free mass ${ }^{(1)}$. Nutritional recommendations for those with type 2 diabetes focus on restricting macronutrients such as carbohydrates and fats with no reduction of protein necessary. Studies have shown increased protein combined with a reduction of carbohydrate intake, improves glucose control reducing hyperglycaemia and post-prandial glucose excursion in type 2 diabetic patients ${ }^{(2)}$.

The importance of food proteins and protein by-products for the management of type 2 diabetes has gained momentum. Food grade proteolytic enzymes can be applied to marine proteins to yield abundant small molecular weight peptides with multifunctional properties. Protein hydrolysates are reported as having superior effects than their intact protein counterparts due to their ability to influence endogenous enzyme activities that affect incretin pathways and diabetes progression.

Here we examined twice-daily $(50 \mathrm{mg} / \mathrm{kg} / \mathrm{bw})$ oral intake of Palmaria palmata protein hydrolysates, produced by proteolytic digestion (Alcalase 2.4L/Flavourzyme 500L (Sigma, Dorset, UK)). Several peptide components from Palmaria palmata hydrolysates have already been identified as having DPP-4 inhibitory actions ${ }^{(3)}$. Here we report the ability of the hydrolysate when taken orally versus oral metformin to improve markers of diabetes in streptozotocin (STZ) induced diabetic mice.

After 9 days, Palmaria palmata hydrolysate $(\mathrm{p}<0.01)$ and metformin $(\mathrm{p}<0.01)$ displayed a significant reduction in non-fasting blood glucose versus the non-treated saline control group, with results persistent until the completion of the study at day 18 (day $18, \mathrm{p}<0.001)$. A reduction in food intake in the Palmaria palmata group was present from day 15 onwards $(\mathrm{p}<0.05)$ but not for metformin. Both treatment groups produced significantly reduced terminal glycated haemoglobin concentrations. Palmaria palmata $(\mathrm{p}<0.01)$ and metformin $(\mathrm{p}<0.001)$ reduced $\mathrm{HbA}_{1 \mathrm{C}}$ by $30 \%$ and $35 \%$ respectively, versus the saline treated control group. After fasting all groups for $12 \mathrm{~h}$ a significant reduction in the mean fasting blood glucose was evident in both the hydrolysate $(12 \mathrm{mmol} / \mathrm{L}, \mathrm{p}<$ $0.01)$ and metformin $(18 \mathrm{mmol} / \mathrm{L}, \mathrm{p}<0.05)$, versus the non-treated saline control group $(27 \mathrm{mmol} / \mathrm{L})$. Weight parameters remained stable over the 18 days in the non-treated control group, whereas weight loss of $8 \%(\mathrm{p}<0.01)$ was seen in the Palmaria palmata group and 5\% $(\mathrm{p}<0.05)$ in the metformin treatment group. Data was analysed using Graphpad Prism 5 deploying students T-test or ANOVA.

While definitive mechanisms of actions are yet to be fully elucidated, this study has presented evidence that proteolytic digests from Palmaria palmata has anti-hyperglycaemic properties resulting in several marked improvements related to diabetes status in mice.

1. Ley SH, Hamdy O, Mohan V, Frank B (2014) Lancet 383(9933), 1999-2007.

2. Gannon MC, Nuttall FQ, Saeed A, Jordan K, Hoover H (2003) Am J Clin Nutr 78(4), 734-741.

3. Harnedy PA, O'Keeffe MB, FitzGerald RJ (2015) Food Chem 72, 400-406. 